\title{
MODEL MATEMATIKA PENGENDALIAN PENYEBARAN PENYAKIT SCHISTOSOMIASIS MENGGUNAKAN ITIK SEBAGAI MUSUH ALAMI BAGI KEONG PERANTARA SCHISTOSOMIASIS
}

\author{
I. Karini' ${ }^{1}$ R. Ratianingsih² \\ 1,2Program Studi Matematika Jurusan Matematika FMIPA Universitas Tadulako \\ Jalan Soekarno-Hatta Km.09 Tondo, Palu 94118, Indonesia \\ 1ipung.karini@gmail.com,2ratianingsih@yahoo.com
}

\begin{abstract}
In Indonesian Schistosomiasis is only found in Central Sulawesi Province, in the highlands of Lindu, the Napu plateau and the Bada plateau, Poso Regency. The disease is caused by the Schistosoma japonicum worm which requires an intermediary host, namely the Oncomelania hupensis lindoensis snail, which is an endemic animal in the area. This study examined mathematically the control of the spread of Schistosomiasis by using ducks as natural enemies for intermediate snails. The human population is divided into vulnerable human subpopulations and a subpopulation of infected humans. Interactions between snail populations and duck populations are expressed as interactions between Predator and Prey. The Schistosoma japonicum worm population is seen as a population growth cycle model. The stability of the model is analyzed using the Jacobi matrix, which is evaluated at a critical point. The model has two critical points $T_{1}$ and $T_{2}$ which represent a disease-free conditions, while $T_{3}$ represents endemic point. Mathematical model simulations controlling the spread of Schistosomiasis. The simulation is using ducks with early populations indicate that disease control by using ducks is less effective because it takes a very long time to be estimated at 55 years.
\end{abstract}

Keywords : Conch Oncomelania Hupensis Lindoensis, Duck, Schistosomiasis, Schistosoma Japonicum Worm.

\section{ABSTRAK}

Di Indonesia Schistosomiasis hanya ditemukan di Provinsi Sulawesi Tengah, di dataran tinggi Lindu, dataran tinggi Napu serta dataran tinggi Bada, Kabupaten Poso. Penyakit ini disebabkan oleh cacing Schistosoma japonicum yang membutuhkan host perantara, yakni keong Oncomelania hupensis lindoensis yang merupakan hewan endemik di daerah tersebut. Penelitian ini mengkaji secara matematis pengendalian penyebaran penyakit Schistosomiasis dengan menggunakan Itik sebagai musuh alami bagi keong perantara. Populasi manusia dibagi menjadi subpopulasi manusia yang rentan dan subpopulasi manusia yang terinfeksi. Interaksi antara populasi keong dan populasi Itik dinyatakan sebagai interaksi antara Predator dan Prey. Adapun populasi cacing Schistosoma japonicum dipandang sebagai model siklus pertumbuhan satu populasi. Kestabilan model dianalisis menggunakan matriks Jacobi yang di evaluasi pada titik kritis. Model memiliki dua titik kritis $T_{1}$ dan $T_{2}$ yang merepresentasikan kondisi bebas penyakit, sedangkan $T_{3}$ merepresentasikan titik endemik. Simulasi model matematika pengendalian penyebaran penyakit Schistosomiasis menggunakan Itik dengan populasi awal 
menunjukkan bahwa pengendalian penyakit dengan menggunakan Itik kurang efektif karena dibutuhkan waktu yang sangat lama yang diperkirakan selama 55 tahun.

Kata Kunci : Keong Oncomelania hupensis lindoensis, Itik, Schistosomiasis, Cacing Schistosoma japonicum.

\section{PENDAHULUAN}

Schistosomiasis merupakan salah satu penyakit menular yang disebabkan oleh cacing darah (cacing trematoda) dari genus Schistosoma sebagai parasit. Menurut WHO (2018) pada tahun 2016, setidaknya ada 206,4 juta penderita Schistosomiasis membutuhkan perawatan, di mana lebih dari 89 juta penderita di laporkan telah diobati. Penyakit ini dapat ditemukan di beberapa daerah endemik Afrika, Amerika Selatan, Caribbean, Brazil, Venezuela, Suriname, China, Indonesia, Filipina, Kamboja, Laos, dan Prancis (WHO, 2017).

Di Indonesia, Schistosomiasis yang disebut juga dengan demam keong, hanya dapat ditemukan di Provinsi Sulawesi Tengah, yaitu di dataran tinggi Lindu, dataran tinggi Napu serta dataran tinggi Bada, Kabupaten Poso. Penyakit ini disebabkan oleh cacing Schistosoma japonicum yang membutuhkan host perantara, yakni keong Oncomelania hupensis lindoensis yang merupakan hewan endemik di daerah tersebut (Hadidjaja, 1985).

Pemutusan rantai penularan Schistosomiasis telah dicanangkan oleh Kementerian Kesehatan Republik Indonesia tahun 2015 melalui program penemuan dini penderita dengan pemeriksaan feses penduduk dan pengobatan. Penduduk yang fesesnya terdapat telur Schistosoma akan diberikan obat Praziquante/ yang efektif melawan semua spesies Schistosoma di dalam tubuh manusia yang terinfeksi penyakit Schistosomiasis (Wei Hu, 2004).

Program pemerintah lainnya yaitu pemberantasan fokus keong perantara baik melalui kegiatan lintas sektor maupun swadaya yang berkelanjutan. Program pemberantasan keong perantara Schistosomiasis dapat dilakukan dengan cara kimiawi yaitu dengan menggunakan moluskisida. Namun, penggunaan moluskisida sintetik memiliki kekurangan yaitu kecenderungan bersifat toksik terhadap lingkungan, biota mikroskopis (zooplankton dan fitoplankton), dan mempengaruhi vegetasi di habitat keong perantara Schistosomiasis. Untuk itu diperlukan cara pengendalian yang lebih ramah lingkungan. Upaya pengendalian yang dapat dilakukan agar tidak merugikan lingkungan adalah dengan menggunakan musuh alami bagi keong Oncomelania hupensis lindoensis yaitu Itik. Pada penelitian yang dilakukan oleh Balai Penelitian dan Pengembangan Pengendalian Penyakit Bersumber Binatang (Litbang P2B2) Donggala, pelepasan Itik di salah satu daerah fokus keong yaitu Desa Mekarsari menunjukkan adanya perbedaan signifikan terhadap banyaknya populasi keong. Terlihat rata - rata populasi keong berfluktuasi selama waktu pengamatan 20 hari. Pada kelompok perlakuan 15 ekor Itik, terlihat penurunan rata rata populasi keong sudah terjadi mulai hari kedua setelah pelepasan Itik sampai hari 20 setelah pelepasan Itik. Pada kelompok perlakuan 10 dan 5 ekor Itik rerata populasi keong juga terlihat 
cenderung turun. Selama waktu pengamatan terjadi perbedaan populasi keong Oncomelania hupensis lindoensis yang signifikan secara statistik, sebelum dan sesudah pelepasan Itik.

Kajian penyebaran penyakit Schistosomiasis dan pengendaliannya menggunakan pemodelan matematika telah dilakukan oleh Sriwahyuni (2016). Penelitian tersebut membahas kendali optimal model siklus hidup cacing Schistosoma japonicum melalui pengobatan dengan prinsip minimum pontryagin. Dalam penelitian ini, selain Praziquante/ sebagai obat bagi penderita yang terinfeksi Schistosomiasis, populasi Itik digunakan pula untuk mengurangi populasi keong Oncomelania hupensis lindoensis. Model matematika yang diadaptasi untuk populasi manusia adalah model Susceptible - Infected (SI). Interaksi antara populasi keong dan populasi Itik mengadaptasi model mangsa - pemangsa (Predator Prey), dimana Itik sebagai musuh alami. Pada populasi cacing Schistosoma japonicum diterapkan model siklus pertumbuhan populasi. Model matematika yang dibangun selanjutnya dianalisa kestabilannya di sekitar titik kritis. Dalam hal persamaan karakteristik yang diperoleh rumit, kestabilan ditentukan melalui kriteria Routh Hurwitz.

\section{METODE PENELITIAN}

1. Memulai penelitian.

2. Mengkaji literatur, bertujuan untuk memperkuat penelitian. Literatur yang digunakan bersumber dari buku-buku, jurnal, dan artikel serta data-data penelitian dan percobaan yang telah dilakukan sebelumnya.

3. Membangun model penyebaran penyakit Schistosomiasis. Model dibangun berdasarkan informasi-informasi yang telah diperoleh dari literatur.

4. Mencari titik kesetimbangan model penyebaran penyakit Schistosomiasis. Titik kesetimbangan dapat ditentukan setelah dibangun model matematika penyebaran penyakit Schistosomiasis, dengan cara meninjau sistem pembangun model pada keadaan stagnan.

5. Menganalisa kestabilan model penyebaran penyakit Schistosomiasis. Setelah titik kesetimbangan diperoleh, langkah selanjutnya adalah menganalisa kestabilan dari model matematika penyebaran penyakit Schistosomiasis untuk mengetahui model tersebut stabil atau tidak.

6. Melakukan simulasi kestabilan dari persamaan model penyebaran penyakit Schistosomiasis.

7. Menyimpulkan hasil penelitian.

8. Selesai.

III. HASIL DAN PEMBAHASAN

\subsection{HASIL}

Model matematika dari pengendalian penyebaran penyakit Schistosomiasis menggunakan Itik sebagai musuh alami bagi keong perantara Schistosomiasis dibangun berdasarkan fakta - fakta dan asumsi. Populasi yang terlibat dalam model matematika adalah populasi manusia, populasi cacing Schistosoma japonicum, populasi Itik, dan populasi keong. 
Populasi manusia dibagi menjadi dua kelompok, yaitu subpopulasi manusia rentan (Susceptible) dan subpopulasi manusia terinfeksi (Infected). Model Matematika yang dikonstruksi pada populasi manusia ini merupakan model Susceptible - Infected (SI). Selanjutnya interaksi yang terjadi antara populasi keong dan populasi Itik mengadaptasi model mangsa - pemangsa (Predator Prey), dimana Itik $\left(I_{K}\right)$ akan berperan sebagai pemangsa dan keong $\left(S_{P}\right)$ yang dimangsa. Sedangkan pada populasi cacing Schistosoma japonicum ditinjau fase perkembangan yang dikelompokkan menjadi cacing dewasa $\left(C_{D}\right)$, telur cacing $\left(C_{T}\right)$, mirasidium $\left(C_{M}\right)$, dan serkaria $\left(C_{S}\right)$. Diagram kompartemen model matematika pengendalian penyebaran Schistosomiasis menggunakan Itik sebagai musuh alami bagi keong perantara Schistosomiasis yang menggambarkan interaksi yang terjadi antara masing - masing kelompok populasi dapat dilihat pada Gambar 1. dengan deskripsi nilai parameter yang terlibat diberikan Tabel 3.

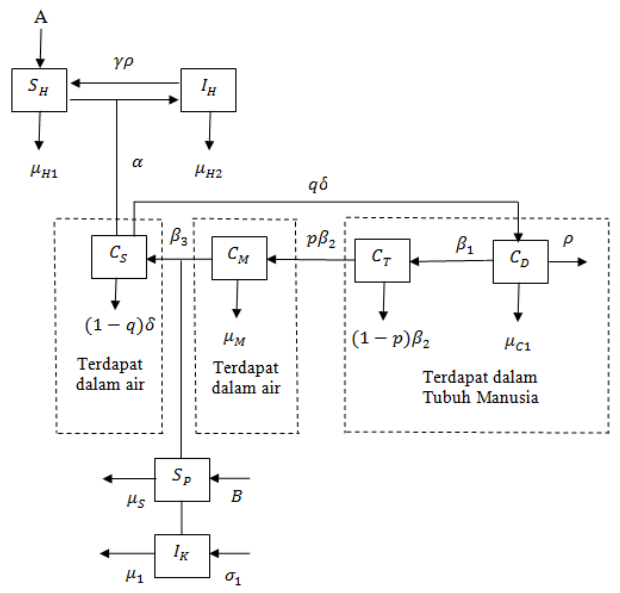

Gambar 1 : Diagram Kompartemen Penyebaran Penyakit Schistosomiasis

Dari diagram tersebut dapat dirumuskan sistem persamaan diferensial untuk model matematika pengendalian penyakit Schistosomiasis menggunakan Itik sebagai musuh alami bagi keong perantara Schistosomiasis sebagai berikut :

$$
\begin{aligned}
\frac{d S_{H}}{d t} & =A+\gamma \rho I_{H}-\alpha S_{H} C_{S}-\mu_{H 1} S_{H} \\
\frac{d I_{H}}{d t} & =\alpha S_{H} C_{S}-\gamma \rho I_{H}-\mu_{H 2} I_{H} \\
\frac{d C_{D}}{d t} & =q \delta C_{S}-\rho C_{D}-\mu_{C 1} C_{D} \\
\frac{d C_{T}}{d t} & =V+\beta_{1} C_{D}-p \beta_{2} C_{T}-(1-p) \beta_{2} C_{T} \\
\frac{d C_{M}}{d t} & =p \beta_{2} C_{T}-\beta_{3} C_{M} S_{P}-\mu_{M} C_{M} \\
\frac{d C_{S}}{d t} & =\beta_{3} C_{M} S_{P}-q \delta C_{S}-(1-q) \delta C_{S} \\
\frac{d S_{P}}{d t} & =B S_{P}-\psi_{1} S_{P} I_{K}-S_{P} \mu_{S} \\
\frac{d I_{K}}{d t} & =\psi_{2} S_{P} I_{K}+\sigma_{1} I_{K}-\mu_{1} I_{K}-\theta_{1} I_{K}{ }^{2}
\end{aligned}
$$


Penyebaran penyakit Schistosomiasis dimulai ketika terjadi infeksi pada manusia rentan $\left(S_{H}\right)$. Infeksi dimulai dari masuknya bentuk infektif (serkaria) menembus kulit manusia. Di dalam tubuh manusia, serkaria $\left(C_{s}\right)$ akan berubah bentuk menjadi schistosomula atau cacing muda yang akan mengikuti sistem peredaran darah, masuk ke dalam jantung kanan, paru-paru, ke dalam jantung kiri dan keluar ke sistem peredaran darah besar dan menjadi cacing dewasa $\left(C_{D}\right)$ di dalam hati. Setelah dewasa, cacing ini kembali ke vena porta dan vena usus dan kemudian cacing betina bertelur setelah berkopulasi (menyatukan alat kelamin jantan dan betina). Telur cacing Schistosoma japonicum $\left(C_{T}\right)$ dapat menembus keluar pembuluh darah, bermigrasi di jaringan dan akhirnya masuk ke dalam lumen usus untuk kemudian ditemukan di dalam feses. Telur menetas dalam air dan larva yang keluar disebut mirasidium $\left(C_{M}\right)$. Mirasidium masuk ke dalam tubuh keong Oncomelania hupensis lindoensis $\left(S_{P}\right)$ dan berkembang menjadi sporokista I dan sporokista II dan kemudian menghasilkan serkaria $\left(C_{s}\right)$. Pada penelitian ini dosis pemberian obat Praziquantel $(\rho)$ diberikan pada penderita yang terinfeksi Schistosomiasis. Selain pemberian obat pada manusia terinfeksi populasi Itik $\left(I_{K}\right)$ juga dilibatkan dalam model sebagai upaya pemberantasan fokus keong perantara Schistosomiasis.

Tabel 1 : Variabel Penelitian

\begin{tabular}{|c|l|}
\hline Variabel & \multicolumn{1}{|c|}{ Keterangan } \\
\hline$S_{H}$ & Manusia Sehat (Rentan) \\
\hline$C_{D}$ & Cacing Schistosoma japonicum Dewasa \\
\hline$C_{T}$ & Telur Cacing Schistosoma japonicum \\
\hline$I_{H}$ & Manusia terinfeksi \\
\hline$I_{K}$ & Itik \\
\hline$C_{M}$ & Mirasidium \\
\hline$C_{S}$ & Serkaria \\
\hline$S_{P}$ & Keong Oncomelania hupensis lindoensis \\
\hline
\end{tabular}

Tabel 2 : Nilai Awal

\begin{tabular}{|c|c|c|c|c|}
\hline Variabel & Deskripsi & $\begin{array}{l}\text { Nilai } \\
\text { Awal }\end{array}$ & Sumber & $\begin{array}{c}\text { Dime } \\
\text { nsi }\end{array}$ \\
\hline$I_{H}(0)$ & Manusia terinfeksi & 1227 & $\begin{array}{c}\text { Roadmap Eradikasi } \\
\text { Schistosomiasis } \\
2018 \text { - } 2025 \\
\text { Desa Mekarsari }\end{array}$ & $\begin{array}{l}\text { Oran } \\
\mathrm{g}\end{array}$ \\
\hline$S_{H}(0)$ & $\begin{array}{l}\text { Manusia Sehat } \\
\text { (Rentan) }\end{array}$ & 1234 & $\begin{array}{c}\text { Roadmap Eradikasi } \\
\text { Schistosomiasis } \\
2018-2025\end{array}$ & $\begin{array}{l}\text { Oran } \\
\mathrm{g}\end{array}$ \\
\hline
\end{tabular}




\begin{tabular}{|c|l|c|c|l|}
\hline & & & Desa Mekarsari & \\
\hline$C_{D}(0)$ & $\begin{array}{l}\text { Cacing Schistosoma } \\
\text { japonicum Dewasa }\end{array}$ & 27 & (Sriwahyuni, et.al, 2016) & Ekor \\
\hline$C_{T}(0)$ & $\begin{array}{l}\text { Telur Cacing } \\
\text { Schistosoma } \\
\text { japonicum }\end{array}$ & 0 & (Windy, 2018) & Butir \\
\hline$I_{K}(0)$ & Itik & 15 & $\begin{array}{c}\text { (P2B2, 2016) } \\
\text { Penelitian Desa } \\
\text { Mekarsari }\end{array}$ & Ekor \\
\hline$C_{M}(0)$ & Mirasidium & 0 & & Ekor \\
\hline$C_{S}(0)$ & Serkaria & 0 & (Rosmini, 2008) & \\
\hline$S_{P}(0)$ & Keong Oncomelania & 308 & & \\
\hline
\end{tabular}

Tabel 3 : Nilai Parameter

\begin{tabular}{|c|c|c|c|c|}
\hline $\begin{array}{l}\text { Para } \\
\text { meter }\end{array}$ & Deskripsi & Nilai & Sumber & $\begin{array}{c}\text { Dimens } \\
\text { i }\end{array}$ \\
\hline$\rho$ & Dosis Pemberian Obat & 0,06 & $\begin{array}{c}\text { Kementrian } \\
\text { Kesehatan RI, } 2018\end{array}$ & Gram \\
\hline$V$ & $\begin{array}{l}\text { Tingkat rekruitmen } \\
\text { pada telur cacing }\end{array}$ & 10 & (Windy, 2018) & Butir \\
\hline$\mu_{H 2}$ & $\begin{array}{l}\text { Laju kematian akibat } \\
\text { infeksi cacing pada } \\
\text { manusia }\end{array}$ & 0,00014 & $\frac{1}{\text { lifetime }}$ & Hari \\
\hline$\delta$ & $\begin{array}{l}\text { Laju transisi dari } \\
\text { serkaria menjadi cacing } \\
\text { dewasa }\end{array}$ & 0,14 & (Hadidjaja, 1982) & Hari \\
\hline$\alpha$ & $\begin{array}{l}\text { Laju infeksi oleh } \\
\text { serkaria }\end{array}$ & 0,03 & $\frac{\text { Jumlah populasi }}{\text { periode waktu }}$ & Menit \\
\hline$\gamma$ & $\begin{array}{l}\text { Laju transisi dari } \\
\text { manusia terinfeksi } \\
\text { kembali rentan }\end{array}$ & 0,01 & $\frac{1}{\text { periode waktu }}$ & Hari \\
\hline$\mu_{H 1}$ & $\begin{array}{l}\text { Laju kematian alami } \\
\text { manusia rentan }\end{array}$ & 0,13 & BPS & $\begin{array}{l}\text { Orang/ } \\
\text { Hari }\end{array}$ \\
\hline$q$ & $\begin{array}{l}\text { Peluang serkaria } \\
\text { menjadi cacing dewasa }\end{array}$ & 0,02 & Asumsi & \\
\hline$\mu_{C 1}$ & Laju kematian alami & 0.000058 & Natadisastra, 2005 & Ekor/ \\
\hline
\end{tabular}




\begin{tabular}{|c|c|c|c|c|}
\hline & cacing dewasa & & & Hari \\
\hline$\mu_{M}$ & $\begin{array}{l}\text { Laju kematian alami } \\
\text { mirasidium }\end{array}$ & 1 & Wicaksono A.,2010 & $\begin{array}{l}\text { Butir/ } \\
\text { Hari }\end{array}$ \\
\hline$\beta_{1}$ & $\begin{array}{l}\text { Laju kelahiran populasi } \\
\text { cacing dewasa }\end{array}$ & 2,3 & $\frac{\text { Populasi yang lahir }}{\text { Periode waktu }}$ & $\begin{array}{l}\text { Ekor/ } \\
\text { Hari }\end{array}$ \\
\hline$\beta_{2}$ & $\begin{array}{l}\text { Laju transisi dari telur } \\
\text { menjadi mirasidium }\end{array}$ & 0,025 & Hadidjaja, 1982 & $\begin{array}{l}\text { Butir/ } \\
\text { Hari }\end{array}$ \\
\hline$p$ & $\begin{array}{l}\text { Peluang telur menjadi } \\
\text { mirasidium }\end{array}$ & 0,4 & Asumsi & \\
\hline$\beta_{3}$ & $\begin{array}{l}\text { Laju transisi dari } \\
\text { mirasidium menjadi } \\
\text { serkaria }\end{array}$ & 0,0167 & Wicaksono A.,2010 & $\begin{array}{l}\text { Buah/ } \\
\text { Hari }\end{array}$ \\
\hline B & $\begin{array}{l}\text { Laju kelahiran keong } \\
\text { Oncomelania hupensis } \\
\text { lindoensis }\end{array}$ & $\begin{array}{c}0,8 \\
\text { (kondisi } \\
\text { tidak stabil } \\
\text { bebas } \\
\text { penyakit dan } \\
\text { kondisi } \\
\text { endemik } \\
\text { stabil) } \\
0,002 \\
\text { (kondisi } \\
\text { stabil bebas } \\
\text { penyakit) }\end{array}$ & $\begin{array}{l}\text { Asumsi syarat eksis } \\
\text { dan syarat stabil }\end{array}$ & $\begin{array}{l}\text { Ekorl } \\
\text { Hari }\end{array}$ \\
\hline$\mu_{S}$ & $\begin{array}{l}\text { Laju kematian alami } \\
\text { keong Oncomelania } \\
\text { hupensis lindoensis }\end{array}$ & $\begin{array}{c}0,002 \\
\text { (kondisi } \\
\text { tidak stabil } \\
\text { bebas } \\
\text { penyakit dan } \\
\text { kondisi } \\
\text { endemik } \\
\text { stabil) } \\
0,8 \\
\text { (kondisi } \\
\text { stabil bebas } \\
\text { penyakit) }\end{array}$ & $\begin{array}{c}\text { Asumsi syarat eksis } \\
\text { dan syarat stabil }\end{array}$ & $\begin{array}{l}\text { Ekor/ } \\
\text { Hari }\end{array}$ \\
\hline
\end{tabular}




\begin{tabular}{|c|c|c|c|c|}
\hline$\theta_{1}$ & $\begin{array}{l}\text { Tingkat perebutan } \\
\text { makanan pada } \\
\text { populasi Itik }\end{array}$ & 0,2 & Dibangkitkan & \\
\hline$\psi_{1}$ & $\begin{array}{l}\text { Laju pemangsaan } \\
\text { keong oleh itik }\end{array}$ & 0,5 & $\frac{\text { Jumlah populasi keong }}{\text { Hari } \times \text { Jumlah Itik }}$ & \\
\hline$\sigma_{1}$ & $\begin{array}{l}\text { Laju pertumbuhan Itik } \\
\text { yang berasal dari } \\
\text { sumber makanan } \\
\text { utama }\end{array}$ & $\begin{array}{c}0,01 \\
\text { (kondisi } \\
\text { tidak stabil } \\
\text { bebas } \\
\text { penyakit, } \\
\text { kondisi } \\
\text { bebas } \\
\text { penyakit } \\
\text { stabil }\left(T_{2}\right) \\
\text { dan kondisi } \\
\text { endemik } \\
\text { stabil) } \\
0,001 \\
\text { (kondisi } \\
\text { stabil bebas } \\
\text { penyakit }\left(T_{1} \text { ) }\right. \\
\text { ) }\end{array}$ & $\begin{array}{l}\text { Asumsi syarat eksis } \\
\text { dan syarat stabil }\end{array}$ & \\
\hline$\psi_{2}$ & $\begin{array}{l}\text { Laju pertumbuhan } \\
\text { populasi itik karena } \\
\text { memangsa keong }\end{array}$ & 0,0001 & Dibangkitkan & \\
\hline$\mu_{1}$ & Laju kematian alami itik & $\begin{array}{c}\text { 0,001 } \\
\text { (kondisi } \\
\text { tidak stabil } \\
\text { bebas } \\
\text { penyakit, } \\
\text { kondisi } \\
\text { bebas } \\
\text { penyakit } \\
\text { stabil }\left(T_{2} \text { ) }\right. \\
\text { dan kondisi } \\
\text { endemik } \\
\text { stabil) }\end{array}$ & $\begin{array}{c}\text { Asumsi syarat eksis } \\
\text { dan syarat stabil }\end{array}$ & Hari \\
\hline
\end{tabular}




\begin{tabular}{|c|l|c|c|c|}
\hline & & & & \\
\hline & & 0,01 & & \\
& & (kondisi & & \\
& & stabil bebas & & \\
& & penyakit $\left(T_{1}\right)$ & & \\
& & ) & & \\
\hline$A$ & Tingkat kelahiran & 0,32 & BPS & \\
& populasi manusia & & & \\
\hline
\end{tabular}

\subsection{PEMBAHASAN}

\subsubsection{Menentukan Titik Kritis}

Titik kritis dari sistem persamaan (1)-(8) dapat diperoleh dengan memandang sistem sebagai suatu keadaan stagnan atau tidak terdapat perubahan dalam populasi, yaitu apabila $\frac{d S_{H}}{d t}=0, \frac{d I_{H}}{d t}=0, \frac{d C_{D}}{d t}=0, \frac{d C_{T}}{d t}=0, \frac{d C_{M}}{d t}=0, \frac{d C_{S}}{d t}=0, \frac{d S_{P}}{d t}=0 \quad$ dan $\quad \frac{d I_{K}}{d t}=0$. Sehingga menghasilkan 3 titik kritis yaitu

$$
\begin{aligned}
& T_{1}=\left(\frac{A}{\mu_{H 1}}, 0,0, \frac{V}{\beta_{2}}, \frac{p V}{\mu_{M}}, 0,0,0\right), T_{2}=\left(\frac{A}{\mu_{H 1}}, 0,0, \frac{V}{\beta_{2}}, \frac{p V}{\mu_{M}}, 0,0, \frac{\sigma_{1}-\mu_{1}}{\theta_{1}}\right), T_{3} \\
&=\left\{\begin{array}{l}
S_{H}=-\frac{\delta A Y\left(\mu_{H 2}+\gamma \rho\right)}{Z}, I H=\frac{W A\left(\rho+\mu_{C 1}\right) \beta_{3} p \alpha V}{Z}, C_{D}=-\frac{\beta_{3} V W q p}{Y}, C_{T}=-\frac{V\left(\rho+\mu_{C 1}\right) W \beta_{3}+\psi_{2} \psi_{1} \mu_{M}}{Y \beta_{2}}, C_{M} \\
=
\end{array}\right. \\
&\left.=-\frac{p V \psi_{2} \psi_{1}\left(\rho+\mu_{C 1}\right)}{Y}, C_{S}=-\frac{W \beta_{3} V\left(\rho+\mu_{C 1}\right) p}{\delta Y}, S_{P}=\frac{W}{\psi_{2} \psi_{1}}, I K=\frac{B-\mu_{S}}{\psi_{1}}\right\}
\end{aligned}
$$

dimana :

$$
W=\left(\left(-\sigma_{1}+\mu_{1}\right) \psi_{1}+\theta_{1}\left(B-\mu_{S}\right)\right)
$$

Syarat untuk $W$ agar $I_{H}, C_{D}, C_{T}, C_{S}$ dan $S_{P}$ bernilai positif yaitu

$W=\left(\left(-\sigma_{1}+\mu_{1}\right) \psi_{1}+\theta_{1}\left(B-\mu_{S}\right)\right)>0$

$R<\frac{B-\mu_{s}}{-\left(-\sigma_{1}+\mu_{1}\right)}$, dengan $R=\frac{\psi_{1}}{\theta_{1}}$

$Y=\left(\left(-\rho+q \beta_{1} p-\mu_{C 1}\right) W \beta_{3}-\psi_{2} \psi_{1} \mu_{M}\left(\rho+\mu_{C 1}\right)\right)$

Syarat untuk $Y$ agar $S_{H}, C_{D}, C_{T}, C_{M}$ dan $C_{S}$ bernilai positif yaitu

$Y=\left(\left(-\rho+q \beta_{1} p-\mu_{C 1}\right) W \beta_{3}-\psi_{2} \psi_{1} \mu_{M}\left(\rho+\mu_{C 1}\right)\right)<0$

$R<-\frac{\beta_{3}\left(-\rho+q \beta_{1} p-\mu_{C 1}\right)\left(B-\mu_{s}\right)}{\left(-\sigma_{1}+\mu_{1}\right)\left(-\rho+q \beta_{1}-\mu_{C}\right) \beta_{3}-\mu_{2} \mu_{1}(\rho+\beta}$

$R<-\frac{\beta_{3}\left(-\rho+q \beta_{1} p-\mu_{C 1}\right) \beta_{3}-\psi_{2} \mu_{M}\left(\rho+\mu_{C 1}\right)}{\left(-\sigma_{1}+\mu_{1}\right)(-\rho+q \rho}$

$Z=-\delta\left(\mu_{H 1}\left(\mu_{H 2}+\gamma \rho\right) Y\right)+\left(V p \mu_{H 2} \alpha\left(\rho+\mu_{C 1}\right) W \beta_{3}\right)$

Syarat untuk $Z$ agar $S_{H}$ dan $I_{H}$ bernilai positif yaitu

$Z=-\delta\left(\mu_{H 1}\left(\mu_{H 2}+\gamma \rho\right) Y\right)+\left(V p \mu_{H 2} \alpha\left(\rho+\mu_{C 1}\right) W \beta_{3}\right)>0$

$R<-\frac{\left(-\delta\left(\mu_{H 2}+\gamma \rho\right)\left(-\rho+q \beta_{1} p-\mu_{C 1}\right) \mu_{H 1}+V p \mu_{H 2} \alpha\left(\rho+\mu_{C 1}\right)\right)\left(B-\mu_{s}\right) \beta_{3}}{-\left(\left(\left(-\sigma_{1}+\mu_{1}\right) \beta_{3}-\psi_{2} \mu_{M}\right) \rho+\left(-\sigma_{1}+\mu_{1}\right)\left(q \beta_{1} p-\mu_{C 1}\right) \beta_{3}-\mu_{C 1} \psi_{2} \mu_{M}\right)\left(\mu_{H 2}+\gamma \rho\right) \delta \mu_{H 1}+V p \mu_{H 2} \alpha \beta_{3}\left(-\sigma_{1}+\mu_{1}\right)\left(\rho+\mu_{C 1}\right)}$

Titik kritis $T_{1}$ dan $T_{2}$ merupakan titik kritis bebas penyakit sedangkan $T_{3}$ merupakan titik kritis endemik penyakit Schistosomiasis. Hasil identifikasi eksistensi titik kritis $T_{1}, T_{2}$ dan $T_{3}$ dinyatakan pada Tabel 4 . 
Tabel 4 : Syarat eksistensi Titik Kritis

\begin{tabular}{|c|c|c|}
\hline $\begin{array}{l}\text { Titik } \\
\text { kritis }\end{array}$ & Syarat eksistensi & $\begin{array}{c}\text { Keteran } \\
\text { gan }\end{array}$ \\
\hline$T_{1}$ & Eksis tanpa syarat & Eksis \\
\hline$T_{2}$ & $\sigma_{1}>\mu_{1}$ & Eksis \\
\hline$T_{3}$ & $\begin{array}{l}B>\mu_{S} \\
R<\frac{B-\mu_{S}}{-\left(-\sigma_{1}+\mu_{1}\right)}, \text { dengan } R=\frac{\psi_{1}}{\theta_{1}} \\
R<-\frac{\beta_{3}\left(-\rho+q \beta_{1} p-\mu_{C 1}\right)\left(B-\mu_{s}\right)}{\left(-\sigma_{1}+\mu_{1}\right)\left(-\rho+q \beta_{1} p-\mu_{C 1}\right) \beta_{3}-\psi_{2} \mu_{M}\left(\rho+\mu_{C 1}\right)} \\
R<-\frac{\left(-\delta\left(\mu_{H 2}+\gamma \rho\right)\left(-\rho+q \beta_{1} p-\mu_{C 1}\right) \mu_{H 1}+V p \mu_{H 2} \alpha\left(\rho+\mu_{C 1}\right)\right)\left(B-\mu_{S}\right) \beta_{3}}{-\left(\left(\left(-\sigma_{1}+\mu_{1}\right) \beta_{3}-\psi_{2} \mu_{M}\right) \rho+\left(-\sigma_{1}+\mu_{1}\right)\left(q \beta_{1} p-\mu_{C 1}\right) \beta_{3}-\mu_{C 1} \psi_{2} \mu_{M}\right)} \\
\quad\left(\mu_{H 2}+\gamma \rho\right) \delta \mu_{H 1}+V p \mu_{H 2} \alpha \beta_{3}\left(-\sigma_{1}+\mu_{1}\right)\left(\rho+\mu_{C 1}\right)\end{array}$ & Eksis \\
\hline
\end{tabular}

Identifikasi titik kritis $T_{3}$ memunculkan pentingnya rasio antara laju pemangsaan keong oleh Itik $\left(\psi_{1}\right)$ dan tingkat perebutan makanan pada populasi itik $\left(\theta_{1}\right)$ yang harus senantiasa dijaga pada ambang

$$
\begin{aligned}
& =\sup \left\{\frac{B-\mu_{s}}{-\left(-\sigma_{1}+\mu_{1}\right)},-\frac{\beta_{3}\left(-\rho+q \beta_{1} p-\mu_{C 1}\right)\left(B-\mu_{s}\right)}{\left(-\sigma_{1}+\mu_{1}\right)\left(-\rho+q \beta_{1} p-\mu_{C 1}\right) \beta_{3}-\psi_{2} \mu_{M}\left(\rho+\mu_{C 1}\right)},\right. \\
& \left.-\frac{\left(-\delta\left(\mu_{H 2}+\gamma \rho\right)\left(-\rho+q \beta_{1} p-\mu_{C 1}\right) \mu_{H 1}+V p \mu_{H 2} \alpha\left(\rho+\mu_{C 1}\right)\right)\left(B-\mu_{s}\right) \beta_{3}}{-\left(\left(\left(-\sigma_{1}+\mu_{1}\right) \beta_{3}-\psi_{2} \mu_{M}\right) \rho+\left(-\sigma_{1}+\mu_{1}\right)\left(q \beta_{1} p-\mu_{C 1}\right) \beta_{3}-\mu_{C 1} \psi_{2} \mu_{M}\right)\left(\mu_{H 2}+\gamma \rho\right) \delta \mu_{H 1}+V p \mu_{H 2} \alpha \beta_{3}\left(-\sigma_{1}+\mu_{1}\right)\left(\rho+\mu_{C 1}\right)}\right\}
\end{aligned}
$$

\subsubsection{Analisis Kestabilan Titik Kritis}

Dengan melakukan analisa kestabilan titik kritis terhadap model matematika pengendalian penyebaran Schistosomiasis menggunakan Itik sebagai musuh alami bagi keong perantara Schistosomiasis pada titik kritis $T_{1}, T_{2}$ dan $T_{3}$ dimana $T_{3}$ dilakukan analisa kestabilannya menggunakan kriteria Routh-Hurwitz. Syarat kestabilan titik kritis dapat dilihat pada Tabel 5 .

Tabel 5 : Syarat eksistensi Titik Kritis

\begin{tabular}{|r|c|c|}
\hline $\begin{array}{r}\text { Titik } \\
\text { kritis }\end{array}$ & Syarat Kestabilan & Keterangan \\
\hline$T_{1}$ & $B<\mu_{s}$ & Stabil \\
& $\sigma_{1}<\mu_{1}$ & \\
\cline { 2 - 3 } & $B>\mu_{s}$ & Tidak \\
& $\sigma_{1}>\mu_{1}$ & Stabil \\
\hline$T_{2}$ & Syarat eksis $T_{2}$ dan & Stabil \\
& $R>\frac{B-\mu_{s}}{-\left(-\sigma_{1}+\mu_{1}\right)}$ & \\
\cline { 2 - 3 } & $R<\frac{B-\mu_{s}}{-\left(-\sigma_{1}+\mu_{1}\right)}$ & Tidak \\
& Syarat eksis $T_{3}$ yaitu: & Stabil \\
\hline$T_{3}$ & Syarat eksis $T_{3}$ dan & Stabil \\
\hline
\end{tabular}




\begin{tabular}{|l|l|l|}
\hline & $\begin{array}{l}a_{1}=R \\
<-\frac{\left(B-\mu_{s}\right) \beta_{3}\left(-\left(\mu_{H 2}+\gamma \rho+\mu_{H 1}\right)\left(-\rho+q \beta_{1} p-\mu_{C 1}\right) \delta+V p \alpha\left(\rho+\mu_{C 1}\right)\right)}{\left.-\left(\mu_{H 2}+\gamma \rho+\mu_{H 1}\right)\left(\left(\sigma_{1}-\mu_{1}\right) \beta_{3}-\psi_{2} \mu_{M}\right) \rho+\left(-\sigma_{1}+\mu_{1}\right)\left(q \beta_{1} p-\mu_{C 1}\right) \beta_{3}-\mu_{C 1} \psi_{2} \mu_{M}\right)} \\
\delta+V p \alpha \beta_{3}\left(-\sigma_{1}+\mu_{1}\right)\left(\rho+\mu_{C 1}\right)\end{array}$ \\
\end{tabular} \mid

\subsubsection{Simulasi Titik Kritis}

Pada penelitian ini dilakukan pula simulasi numerik dari solusi model matematika pengendalian penyebaran penyakit Schistosomiasis menggunakan Itik sebagai musuh alami bagi keong perantara. Simulasi dilakukan dengan memberikan nilai - nilai parameter yang memenuhi syarat eksistensi dan syarat kestabilan dari titik kritis (Tabel 4. dan Tabel 5.), serta nilai awal variabel dan nilai parameter pada Tabel (2) dan (3.).

Simulasi kondisi bebas penyakit direpresentasikan oleh titik kritis $T_{1}$ dengan nilai awal $I_{H}(0)=1227, S_{H}(0)=1234, C_{D}(0)=27, C_{T}(0)=0, I_{K}(0)=15, C_{M}(0)=$ $0, C_{S}(0)=0, S_{P}(0)=308$ untuk interval waktu 365 hari. Titik kritis $T_{1}$ dikatakan stabil jika seiring dengan perubahan waktu kurva solusi mendekati titik kritisnya yaitu $(2,0,0,400,4,0,0,0)$.
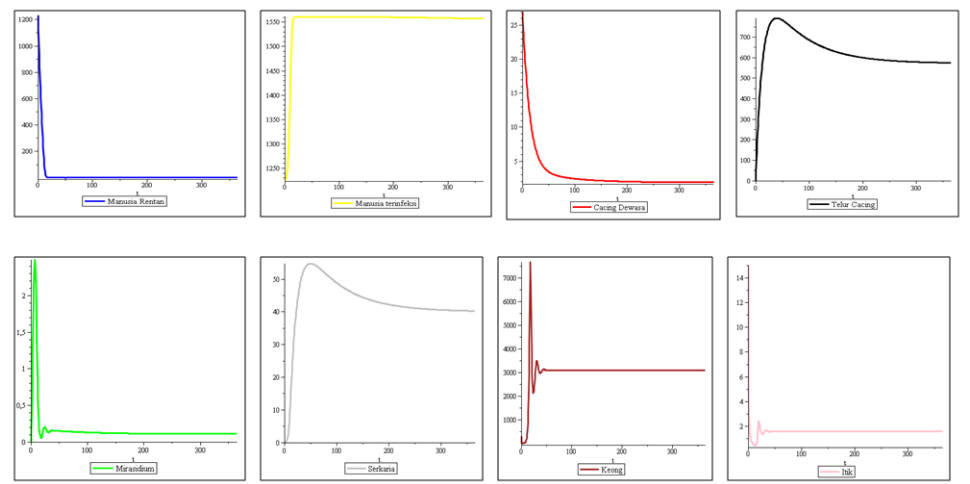

Gambar 2 : Simulasi Pertumbuhan Populasi $T_{1}$ Tidak Stabil

Kurva solusi manusia rentan $\left(S_{H}\right)$, manusia terinfeksi $\left(I_{H}\right)$, Cacing dewasa $\left(C_{D}\right)$, Telur cacing $\left(C_{T}\right)$, Mirasidium $\left(C_{M}\right)$, Serkaria $\left(C_{S}\right)$, Itik $\left(I_{K}\right)$, Keong Oncomelania hupensis lindoensis $\left(S_{P}\right)$ tidak konvergen ke nilai titik kritisnya pada hari ke 365 . Hal ini memberikan arti bahwa $T_{1}$ tidak stabil. Simulasi kondisi bebas penyakit direpresentasikan oleh titik kritis $T_{1}$ dengan nilai awal $I_{H}(0)=1227, S_{H}(0)=1234$, $C_{D}(0)=27, C_{T}(0)=0, I_{K}(0)=15, C_{M}(0)=0, C_{S}(0)=0, S_{P}(0)=308$ untuk interval waktu 365 hari. Titik kritis $T_{1}$ dikatakan stabil jika seiring dengan perubahan waktu kurva solusi mendekati titik kritisnya yaitu $(2,0,0,400,4,0,0,0)$. 

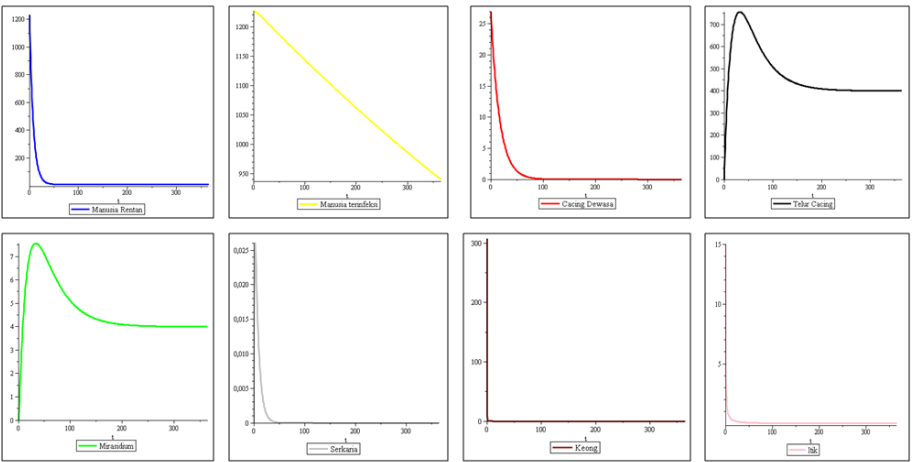

Gambar 3 : Simulasi Pertumbuhan Populasi $T_{1}$ Stabil

Kurva solusi manusia rentan $\left(S_{H}\right)$, Cacing dewasa $\left(C_{D}\right)$, Telur cacing $\left(C_{T}\right)$, Mirasidium $\left(C_{M}\right)$, Serkaria $\left(C_{s}\right)$, Itik $\left(I_{K}\right)$, Keong Oncomelania hupensis lindoensis $\left(S_{P}\right)$ konvergen ke nilai titik kritisnya pada hari ke 365 . Hal ini memberikan arti bahwa $T_{1}$ stabil. Kurva solusi manusia terinfeksi $\left(I_{H}\right)$ konvergen menuju ke titik kritisnya pada hari ke 19800.

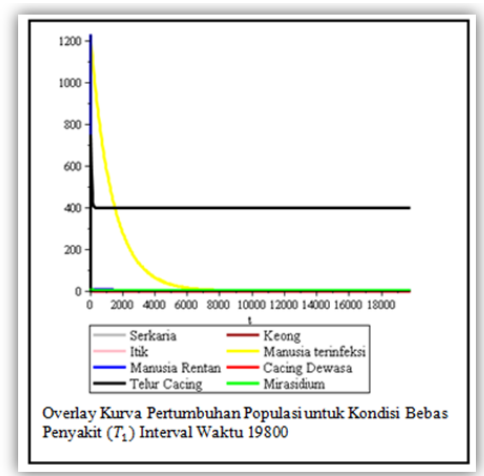

(a)

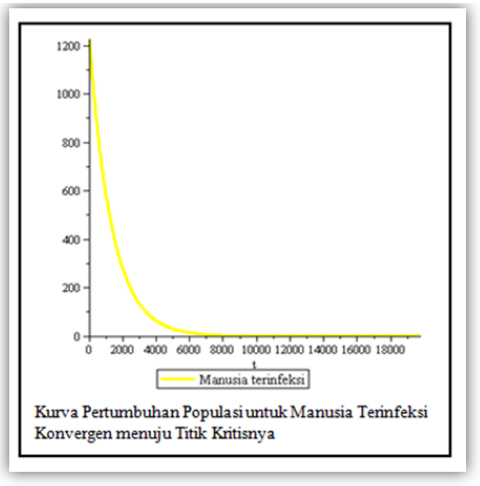

(b)

Gambar 4 : a. Overlay kurva Pertumbuhan Populasi untuk Kondisi Bebas Penyakit $\left(T_{1}\right)$ Interval 19800, b. Kurva Pertumbuhan Populasi untuk Manusia Terinfeksi Konvergen menuju Titik Kritisnya

Simulasi kondisi bebas penyakit direpresentasikan oleh titik kritis $T_{2}$ dengan nilai awal $I_{H}(0)=1227, S_{H}(0)=1234, C_{D}(0)=27, C_{T}(0)=0, I_{K}(0)=15, C_{M}(0)=$ $0, C_{S}(0)=0, S_{P}(0)=308$ untuk interval waktu 365 hari. Titik kritis $T_{2}$ dikatakan stabil jika seiring dengan perubahan waktu kurva solusi mendekati titik kritisnya yaitu $(2,0,0,400,4,0,0,0)$. 

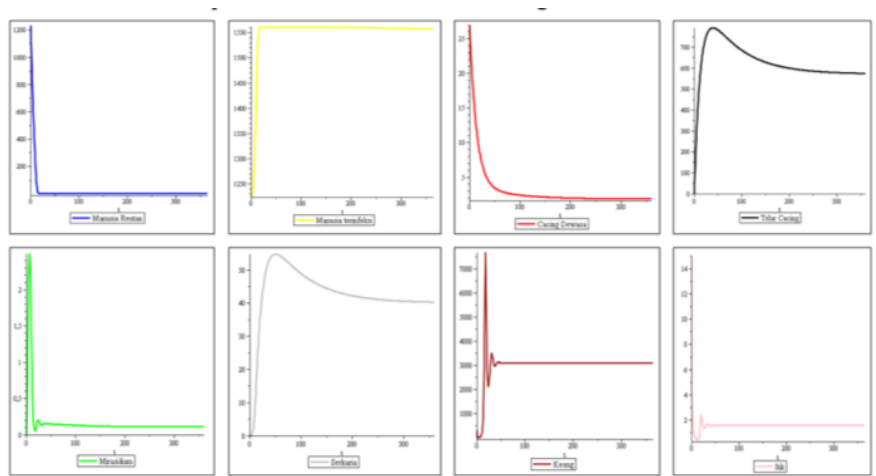

Gambar 5 : Simulasi Pertumbuhan Populasi $T_{2}$ Tidak Stabil

Kurva solusi manusia rentan $\left(S_{H}\right)$, manusia terinfeksi $\left(I_{H}\right)$, Cacing dewasa $\left(C_{D}\right)$, Telur cacing $\left(C_{T}\right)$, Mirasidium $\left(C_{M}\right)$, Serkaria $\left(C_{S}\right)$, Itik $\left(I_{K}\right)$, Keong Oncomelania hupensis lindoensis $\left(S_{P}\right)$ tidak konvergen ke nilai titik kritisnya pada hari ke 365 . Hal ini memberikan arti bahwa $T_{2}$ tidak stabil. Simulasi kondisi bebas penyakit yang direpresentasikan oleh titik kritis $T_{2}$ menggunakan nilai awal $I_{H}(0)=1227, S_{H}(0)=$ $1234, C_{D}(0)=27, C_{T}(0)=0, I_{K}(0)=15, C_{M}(0)=0, C_{S}(0)=0, S_{P}(0)=30$ interval waktu 365 hari.
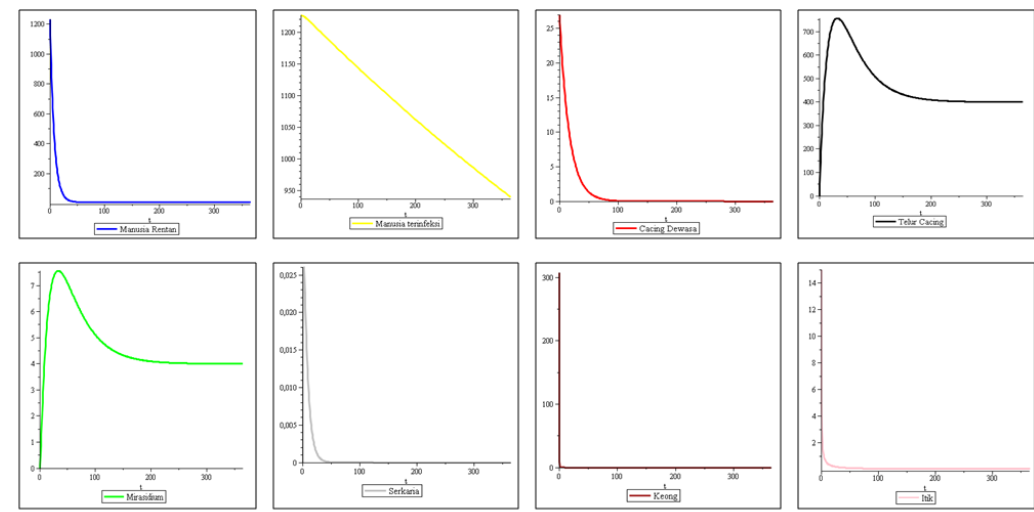

Gambar 6 : Simulasi Pertumbuhan Populasi $T_{2}$ Stabil

Kurva solusi manusia rentan $\left(S_{H}\right)$, Cacing dewasa $\left(C_{D}\right)$, Telur cacing $\left(C_{T}\right)$, Mirasidium $\left(C_{M}\right)$, Serkaria $\left(C_{S}\right)$, Itik $\left(I_{K}\right)$, Keong Oncomelania hupensis lindoensis $\left(S_{P}\right)$ konvergen ke nilai titik kritisnya pada hari ke 365. Hal ini memberikan arti bahwa $T_{2}$ stabil. Kurva solusi manusia terinfeksi $\left(I_{H}\right)$ konvergen menuju ke titik kritisnya pada hari ke 19800. 


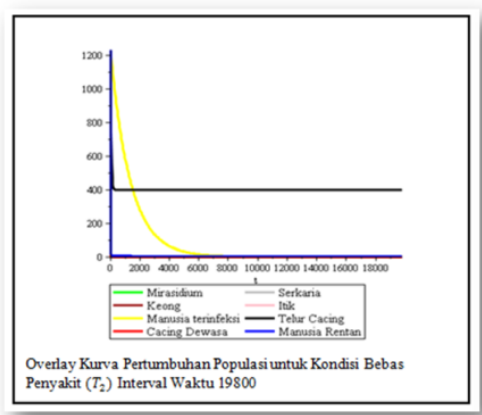

(a)

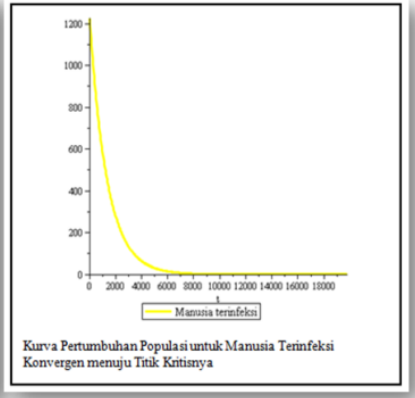

(b)

Gambar 7: a. Overlay kurva Pertumbuhan Populasi untuk Kondisi Bebas Penyakit $\left(T_{2}\right)$ Interval 19800, b. Kurva Pertumbuhan Populasi untuk Manusia Terinfeksi

Konvergen menuju Titik Kritisnya

Simulasi kondisi endemik yang direpresentasikan oleh titik kritis $T_{3}$ menggunakan nilai awal $I_{H}(0)=1227, S_{H}(0)=1234, C_{D}(0)=27, C_{T}(0)=0, I_{K}(0)=$ $15, C_{M}(0)=0, C_{S}(0)=0, S_{P}(0)=308$ untuk interval waktu 365 hari. Titik kritis $T_{3}$ dikatakan stabil jika seiring dengan perubahan waktu kurva solusi mendekati titik tersebut.
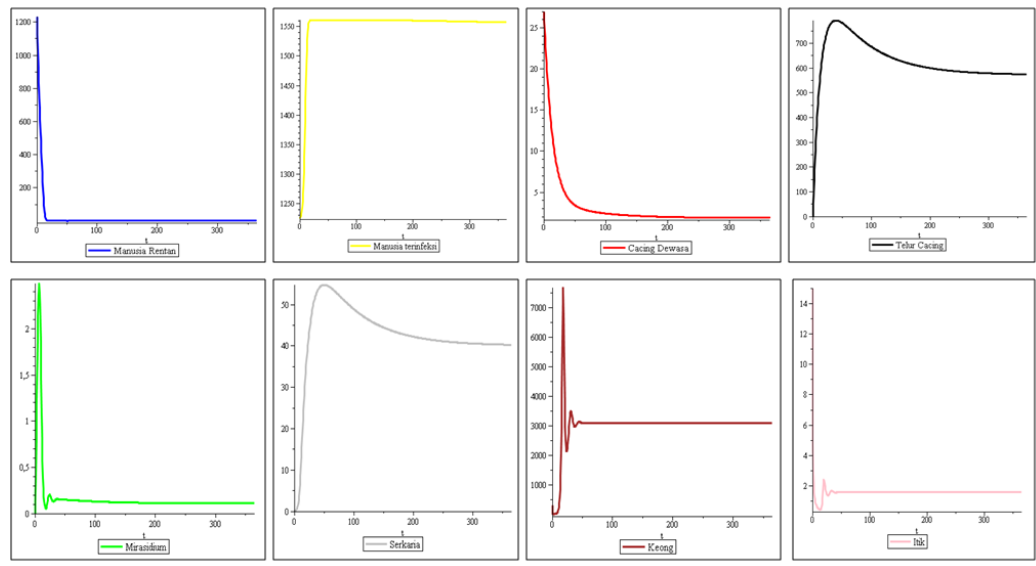

Gambar 8 : Simulasi Pertumbuhan Populasi $T_{3}$ Stabil

Kurva solusi manusia rentan $\left(S_{H}\right)$, Cacing dewasa $\left(C_{D}\right)$, Telur cacing $\left(C_{T}\right)$, Mirasidium $\left(C_{M}\right)$, Serkaria $\left(C_{s}\right)$, Itik $\left(I_{K}\right)$, Keong Oncomelania hupensis lindoensis $\left(S_{P}\right)$ konvergen ke nilai titik kritisnya pada hari ke 365. Hal ini memberikan arti bahwa $T_{3}$ stabil. Kurva solusi manusia terinfeksi $\left(I_{H}\right)$ konvergen menuju ke titik kritisnya pada hari ke 19800. 


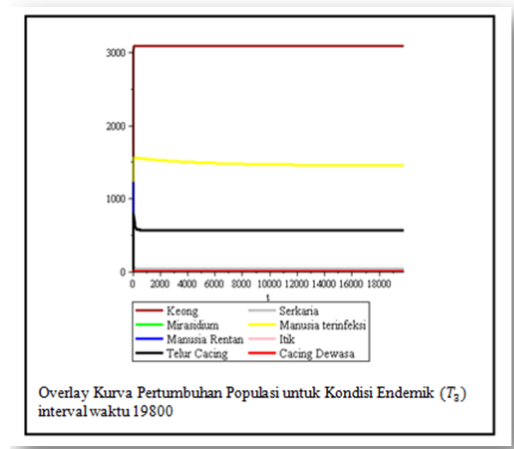

(a)

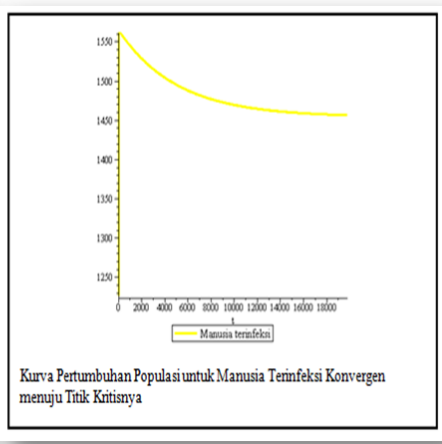

(b)

Gambar 9 : a. Overlay kurva Pertumbuhan Populasi untuk Kondisi Bebas Penyakit $\left(T_{3}\right)$ Interval 19800, b. Kurva Pertumbuhan Populasi untuk Manusia Terinfeksi Konvergen menuju Titik Kritisnya

Pengendalian Penyebaran Penyakit Schistosomiasis Menggunakan Itik Sebagai Musuh Alami Bagi Keong Perantara Schistosomiasis tidak efektif karena lamanya waktu yang dibutuhkan untuk pengendalian Keong Oncomelania hupensis lindoensis dengan menggunakan Itik, sehingga harus dilakukan cara lain agar pengendalian penyakit Schistosomiasis berjalan dengan efektif.

\section{KESIMPULAN}

Penelitian ini telah mengkonstruksi model matematika pengendalian penyebaran penyakit Schistosomiasis menggunakan Itik sebagai musuh alami bagi keong perantara Schistosomiasis. Dari model tersebut diperoleh 3 titik kritis dimana titik kritis pertama dan kedua merupakan titik kritis bebas penyakit sedangkan titik kritis ketiga merupakan titik kritis endemik penyakit Schistosomiasis. Hasil uji kestabilan pada titik kritis dapat diketahui bahwa Titik kritis $T_{1}$ eksis tanpa syarat tetapi $T_{1}$ stabil dengan syarat, Titik kritis $T_{2}$ eksis dengan syarat. Syarat eksistensi $T_{2}$ merupakan syarat stabilnya dengan tambahan syarat kestabilan, Titik kritis $T_{3}$ eksis dengan syarat. Syarat eksistensi $T_{3}$ merupakan syarat stabilnya dengan tambahan syarat stabil. Simulasi titik kritis menunjukkan bahwa Pengendalian penyebaran penyakit Schistosomiasis menggunakan Itik sebagai musuh alami bagi keong perantara Schistosomiasis tidak efektif karena lamanya waktu yang dibutuhkan untuk pengendalian Keong Oncomelania hupensis lindoensis. 


\section{DAFTAR PUSTAKA}

[1]. Balai Penelitian dan Pengembangan Pengendalian Penyakit Bersumber Binatang Donggala, Pedoman Pengendalian Schistosomiasis, 2018, Provinsi Sulawesi Tengah Kota Palu.

[2]. Hadidjaja, P.,Schistosomiasis di Sulawesi Tengah Indonesia, Fakultas Kedokteran Universitas Indonesia, 1985, Jakarta.

[3]. Hu W., P.J. Brindley, D.P. McManus, Z. Feng, and Ze-Guang Han, Schistosome Transcriptomes: New Insights Into the Parasite and Schistosomiasis. TRENDS in Molecular Medicine, 10 (5),2004, 217-225.

[4]. Sriwahyuni, dkk., Kendali Optimal Model Siklus Hidup Cacing Schistosoma japonicum dengan Prinsip Minimum Pontryagin, 2016, Palu: Jurusan Matematika FMIPA Universitas Tadulako.

[5]. [WHO] World Health Organization, Schistosomiasis, 2017, Diperoleh dari website Wolrd Health Organization : http://www.who.int/mediacentre/factsheets/fs115/en/, Di akses 4 Februari 2018.

[6]. [WHO] World Health Organization, Schistosomiasis, 2018, Diperoleh dari website Wolrd Health Organization : http://www.who.int/mediacentre/factsheets/fs115/en/, Di akses 8 September 2018. 